\title{
AMCP Partnership Forum: Racial health disparities-a closer look at benefit design
}

\section{SUMMARY}

As part of its stand against racial injustice and its commitment to action, AMCP dedicated a partnership forum to discussion of potential sources of racial health disparities and inequities in benefit design because these are primary drivers of medication use. This forum, held virtually March 23-24, 2021, convened more than 40 experts representing key stakeholders from managed care settings. Key principles that emerged from the forum discussion as means to mitigate racial health disparities were to acknowledge that structural racism exists and that it can impact the provision of health care, including but not limited to formulary development and benefit design processes; to integrate proactive strategies to improve equity, beginning with education and training, into all aspects of health care; and to view patients holistically with an understanding of the compounding effect of social determinants of health on their personal wellness.

With these principles in mind, participants highlighted several priority considerations including improving existing gaps in data, addressing diversity and equity as they relate to formulary development, evaluating systems such as benefit offerings through a lens of increasing equity, recognizing cost-related factors that affect equity, considering patients' interactions with and their ability to access the system, and committing to patient-centered care. Participants also suggested areas for policy-related focus and noted the need to develop and deploy specific education and training.

\section{Forum participants}

Rebekah Angove, PhD, Vice President, Patient Experience and Program Evaluation, Patient Advocate Foundation; Angela Banks, Vice President, External Affairs, UnitedHealth Group; Christina Barrington, PharmD, Vice President, Pharmacy Programs, Priority Health; Maribeth Bettarelli, PharmD, Senior Director, Quality and Accreditation, CVS Caremark; Diana Brixner, RPh, PhD, FAMCP, Professor, Department of Pharmacotherapy, University of Utah Pharmacotherapy Outcomes Research Center; Kathryn Brown, PharmD, MHA, Vice President, Pharmacy, Interim Chief Pharmacy Officer, Kaiser Permanente; Patrick Campbell, PharmD, PhD, Senior Director, Research, Pharmacy Quality Alliance; Lisa Cashman, PharmD, Vice President, Specialty Solutions, MedImpact Direct, LLC; Susmita Chavala, PharmD, MHA, Senior Director, Clinical Policy Development \& Drug List Management, Prime Therapeutics; Jessica Daw, PharmD, MBA, Vice President, Pharmacy, Sentara Health Plans; Nicole Dawley, RPh, Director, Pharmacy Clinical Strategy \& Policy, Excellus BlueCross BlueShield; Lynn Deguzman, PharmD, Pharmacy Clinical Operations Manager, Kaiser Permanente; Eric Gascho, Vice President, Policy and Government Affairs, National Health Council; Fred Goldstein, MS, President, Accountable Health, LLC; Jennifer Graff, PharmD, Vice President, Policy Research, National Pharmaceutical Council; Angela Hagan, PhD, Associate Director, Population Health Strategy, Humana, Inc.; Dorothy Hoffman, MPP, Access Innovation Lead, Pfizer; Paul Jeffrey, PharmD, Director of Pharmacy, MassHealth/UMass Medical School; Sharon Jhawar, PharmD, MBA, BCGP, Chief Pharmacy Officer, SCAN Health Plan; Stephen Kogut, PhD, MBA, $\mathrm{RPH}$, Professor, University of Rhode Island College of Pharmacy; David Kountz, MD, MBA, Co-Chief Academic Officer, Hackensack Meridian Health; Sandra
Leal, PharmD, MPH, CDCES, EVP, Tabula Rasa HealthCare; Lisa Le Gette, RPh, MBA, Government Affairs Principal, Cigna; Brian Lehman, MBA, MHA, RPh, Director, Patient Advocacy and Strategic Alliances, Sandoz, Inc.; Lauren Lyles-Stolz, PharmD, Executive Director, Pharmacy Quality Assurance Commission, Washington State Department of Health; Jacquelyn McRae, PharmD, MS, Director, Policy, Research, and Membership, PhRMA; Bhavesh Modi, RPh, Vice President, Pharmacy, Healthfirst; Lilian Ndehi, PharmD, MBA, BCPS, Associate Vice President, Patient Safety and Pharmacy Stars, Humana, Inc.; Laura Pizzi, PharmD, MPH, Professor and Director, Health Outcomes, Policy, and Economics Program, Rutgers University; Bryan Powell, MBA, CPHQ, Director, Value \& Access, Amgen, Inc.; Lauren Powell, PhD, MPA, Vice President, US Health Equity \& Community Wellness, Takeda; Prabashni Reddy, Director, Center for Drug Policy, Mass General Brigham; Vimal Reddy, PharmD, Senior Director, Formulary Strategy, OptumRx; Marissa Schlaifer, MS, RPh, Vice President, Policy and Regulatory Affairs, OptumRx; Annie Schuster, PharmD, Senior Director, Clinical Pharmacy Programs, Cigna; Tim Suther, Senior Vice President, General Manager, Data Solutions, Change Healthcare; Gretchen C. Wartman, BA, Vice President for Policy and Program, National Minority Quality Forum; and Claire Wulf Winiarek, Vice President of Policy, Pharmaceutical Care Management Association.

\section{CORRESPONDENCE:}

Vyishali Dharbhamalla, PharmD, AMCP, 703.684.2633; vdharbhamalla@amcp.org

J Manag Care Spec Pharm. 2022;28(1):125-31

Copyright $(2022$, Academy of Managed Care Pharmacy. All rights reserved. 


\begin{tabular}{|c|c|}
\hline Term & Definitiona $^{a}$ \\
\hline $\begin{array}{l}\text { Cultural } \\
\text { competence }\end{array}$ & $\begin{array}{l}\text { A set of congruent behaviors, attitudes, and policies that come together in a system, agency, or among professionals that } \\
\text { enables effective work in cross-cultural situations } \\
\text { Source: CDC, National Prevention Information Network (https://npin.cdc.gov/pages/cultural-competence) }\end{array}$ \\
\hline Equality & The state of being equal, especially in status, rights, and opportunities \\
\hline Equity & $\begin{array}{l}\text { Absence of avoidable or remediable differences among groups of people, whether those groups are defined socially, } \\
\text { economically, demographically, or geographically. Health inequities therefore involve more than inequality with respect to } \\
\text { health determinants, access to the resources needed to improve and maintain health or health outcomes. They also entail a } \\
\text { failure to avoid or overcome inequalities that infringe on fairness and human rights norms } \\
\text { Source: WHO (https://www.who.int/healthsystems/topics/equity/en/) }\end{array}$ \\
\hline Ethnicity & The fact or state of belonging to a social group that has a common national or cultural tradition \\
\hline $\begin{array}{l}\text { Health care } \\
\text { disparity }\end{array}$ & $\begin{array}{l}\text { Differences in access to or availability of medical facilities and services and variation in rates of disease occurrence } \\
\text { and disabilities between population groups defined by socioeconomic characteristics such as age, ethnicity, economic } \\
\text { resources, or gender and populations identified geographically } \\
\text { Source: AHRQ (https://www.ahrq.gov/topics/disparities.html) }\end{array}$ \\
\hline $\begin{array}{l}\text { Health } \\
\text { disparity }\end{array}$ & $\begin{array}{l}\text { Differences in health status between people related to social or demographic factors such as race, gender, income, or } \\
\text { geographic region } \\
\text { Source: APHA (https://www.apha.org/topics-and-issues/health-equity) }\end{array}$ \\
\hline $\begin{array}{l}\text { Health } \\
\text { equity }\end{array}$ & $\begin{array}{l}\text { Everyone has the opportunity to attain their highest level of health } \\
\text { Source: APHA (https://www.apha.org/topics-and-issues/health-equity) }\end{array}$ \\
\hline $\begin{array}{l}\text { Health insurance } \\
\text { equity }\end{array}$ & $\begin{array}{l}\text { Designing insurance coverage in a way that provides access to care for people who need it when they need it, recognizing } \\
\text { that clinical need is an essential factor in determining where to direct resources, and that does not apologize for treating } \\
\text { people with different needs differently } \\
\text { Source: Health Affairs (https://www.healthaffairs.org/do/10.1377/hblog } 20170522.060211 / \text { full/) }\end{array}$ \\
\hline $\begin{array}{l}\text { Health insurance } \\
\text { literacy }{ }^{10}\end{array}$ & $\begin{array}{l}\text { A person's ability to seek, obtain, and understand health insurance plans; and once enrolled they use their insurance to } \\
\text { seek appropriate health care services }\end{array}$ \\
\hline
\end{tabular}

In June 2020, AMCP joined 13 other national pharmacy organizations in a joint statement in which they took a stand against racial injustice and committed to goals to ensure that the care provided by pharmacists and within pharmacies upholds the highest standards. ${ }^{1,2}$ These goals included working together to provide opportunities to address health care disparities and strengthen affected communities; educating pharmacists, student pharmacists, and pharmacy technicians on social injustices and systematic challenges impacting health care; delivering strategies that focus on change through communications, partnerships, and solutions to address health care disparities; and continuing dialogue among pharmacy organizations and stakeholders in order to identify and implement change. ${ }^{2}$ At the same time, AMCP recognized that these goals would need to be translated into specific, long-term actions that improve patient outcomes and ensure that we are collectively accountable for health equity among all Americans, including Black Americans, indigenous people, and people of color. ${ }^{3}$

AMCP continued to underscore the need to address racial disparities with a call for submissions to the Journal of Managed Care+Specialty Pharmacy; JMCP editors invited papers that would help continue and advance difficult but essential conversations around disparities in medication use. ${ }^{4,5}$ One article, which appeared in the journal's November 2020 issue, helped further define this mission by providing an outline for addressing racial disparities in medication use, which includes acknowledging that these disparities exist and taking steps to improve them by developing coverage policies, program designs, and quality initiatives in consultation with those who are affected by disparity; reducing cost-sharing for essential medications; and supporting federal and state efforts to limit out-of-pocket medication costs. ${ }^{4,6} \mathrm{AMCP}$ and the AMCP Foundation also began to weave measurable social justice goals into their strategic plans and initiatives. ${ }^{4,7}$ For 


\begin{tabular}{|c|c|}
\hline Term & Definitiona \\
\hline ealth literacy & $\begin{array}{l}\text { Personal health literacy is the degree to which individuals have the ability to find, understand, and use information and } \\
\text { services to inform health-related decisions and actions for themselves and others } \\
\text { Organizational health literacy is the degree to which organizations equitably enable individuals to find, understand, and } \\
\text { use information and services to inform health-related decisions and actions for themselves and others } \\
\text { Source: DHHS Office of Disease Prevention and Health Promotion (https://health.gov/our-work/healthy-people/healthy- } \\
\text { people-2030/health-literacy-healthy-people-2030) }\end{array}$ \\
\hline $\begin{array}{l}\text { Institutional } \\
\text { (structural) } \\
\text { racism } 11\end{array}$ & Differential access to the goods, services, and opportunities of society by race \\
\hline Microaggression & $\begin{array}{l}\text { A statement, action, or incident regarded as an instance of indirect, subtle, or unintentional discrimination against members } \\
\text { of a marginalized group such as a racial or ethnic minority }\end{array}$ \\
\hline Race & $\begin{array}{l}\text { Classification of humans into groups based on physical traits, ancestry, and social relations, or the relationships between } \\
\text { them }\end{array}$ \\
\hline Racism & $\begin{array}{l}\text { Prejudice, discrimination, or antagonism directed against a person or people on the basis of their membership in a } \\
\text { particular racial or ethnic group, typically one that is a minority or marginalized }\end{array}$ \\
\hline $\begin{array}{l}\text { Sexual } \\
\text { orientation and } \\
\text { gender identity }\end{array}$ & $\begin{array}{l}\text { Collecting data related to sexual orientation and gender identity in electronic health records is essential to providing high- } \\
\text { quality, patient-centered care } \\
\text { Source: CDC (https://www.cdc.gov/hiv/clinicians/transforming-health/health-care-providers/collecting-sexual-orientation. } \\
\text { html) }\end{array}$ \\
\hline $\begin{array}{l}\text { Social } \\
\text { determinants } \\
\text { of health }\end{array}$ & $\begin{array}{l}\text { The conditions in the environment where people are born, live, learn, work, play, worship, and age that affect a wide range } \\
\text { of health functioning and quality-of-life outcomes and risks. These can be grouped into } 5 \text { domains: economic stability, } \\
\text { education access and quality, health care access and quality, neighborhood and built environment, social and community } \\
\text { context } \\
\text { Source: DHHS Office of Disease Prevention and Health Promotion (https://health.gov/healthypeople/objectives-and-data/ } \\
\text { social-determinants-health) }\end{array}$ \\
\hline
\end{tabular}

aThe Oxford Languages Dictionary is the source of definitions unless otherwise noted.

$A H R Q=$ Agency for Healthcare Research and Quality; $A P H A=$ American Public Health Association; $C D C=$ Centers for Disease Control and Prevention; DHHS=US Department of Health and Human Services; $W H O=$ World Health Organization.

example, they developed an equity, diversity, and inclusion statement to guide planning and dedicated a partnership forum to discussion of potential sources of racial health disparities and inequities in benefit design, as these are primary drivers of medication use. ${ }^{4}$

This forum, held virtually March 23-24, 2021, convened more than 40 experts who represented payers, pharmacy benefit managers, integrated delivery systems, and biopharmaceutical manufacturers; they were health economists and analysts, patient advocates, academicians, and other key stakeholders from managed care settings. Throughout the 2 days, these expert participants attended panel sessions that gave them opportunities to ask and answer questions and to provide additional feedback via chat and small-group breakout sessions followed by reportouts and discussion among the broader group.

Forum participants were asked to (1) identify challenges and opportunities related to racial health disparities within benefit design and formulary processes; (2) identify potential interventions to address racial health disparities in managed care pharmacy; and (3) develop recommendations to address racial health disparities in education and training programs within managed care pharmacy.

\section{Priority Considerations to Advance Equity in Formulary and Benefit Design}

Several key principles emerged from the forum discussion as means to mitigate racial health disparities; these are expounded upon throughout this report. One principle is to acknowledge that structural racism exists and that it can impact the provision of health care, including but not limited to formulary development and benefit design. Another is that proactive strategies to improve equity, beginning with education and training, must be integrated into all aspects of health care. A third is that patients must 


\section{TABLE 2 CHARGE2 Framework for Health Care Workers to Mitigate Bias}

\begin{tabular}{c|l}
\hline C & Change your context: Is there another perspective that is possible? \\
\hline H & Be honest: With yourself, acknowledge and be aware \\
\hline A & Avoid blaming yourself: Know that you can do something about it \\
\hline R & Realize when you need to slow down \\
\hline G & Get to know people you perceive as different from you \\
\hline E & Engage: Remember why you are doing this \\
\hline E & Empower patients and peers \\
\hline Source: DallaPiazza et al.9
\end{tabular}

be viewed holistically, with an understanding of the compounding effect of social determinants of health on their personal wellness.

Forum participants emphasized early in the discussion the importance of having an understanding of terminology related to building greater equity-such as those terms used throughout the forum (Table 1)-and historical examples of structural racism, how they persist, and how they affect current health care practice. One striking example was one study's conclusion that false beliefs about the biological differences between Blacks and Whites among medical students and residents led them to report lower pain ratings for their Black patients, which the authors suggested may contribute to racial disparities in pain treatment. ${ }^{8}$ Participants recognized, however, that an opportunity lies in adopting published frameworks to address and cope with such racial bias in health care settings. Two of those frameworks presented during the forum are CHARGE2 (Table 2) and INTERRUPT (Table 3), which include such tenets as advocate; build trust, empathy, and self-efficacy into provider-patient relationships; learn and teach others; mitigate unconscious or implicit bias; and create nonthreatening strategies to address bias during clinical encounters. $^{9}$
With this foundation in mind, participants highlighted a set of priority considerations to advance equity in formulary and benefit design (Table 4). Among the most important of these is the need to fill existing gaps in data. This need is especially relevant for both clinical trials and real-world evidence, and forum participants called for increased diversity among enrolled study participants, stronger trial designs that better detect possible heterogeneity in patient responses, and expanded subgroup reporting to inform more nuanced formulary evidence reviews. Participants also raised considerations with respect to augmenting the data available within health care delivery systems by, for instance, more thoroughly and efficiently collecting patient demographic information into medical records; they acknowledged, however, that collection and utilization of that data must be balanced with patient privacy concerns and were aware that biases may be unintentionally built into current algorithms and artificial intelligence platforms. Additionally, participants suggested that having available more robust health outcomes data by racial and ethnic group and incorporating those data into drug monograph tools used in formulary development-for example, the AMCP Format or monograph templates-would support diversity and equity. Further suggestions to improve this process included providing annual equity training for pharmacy and therapeutics committee members, having committee representation that reflects an organization's minority membership, adding a member with expertise in equity, creating a subcommittee to evaluate equity in formulary decisions, and engaging patient voices from disadvantaged groups in order to share their experiences and feedback.

Participants also saw value in evaluating other existing systems through a lens of increasing equity (or acknowledging patient differences), driving a shift from the standard of equality (or treating all patients the same) that they suggested is primarily in place today. This could include involving partners such as consultants and other stakeholders to update benefit designs and allow benefit flexibility, particularly considering the evolving landscape of higher-cost specialty medications, or populations for whom some medications may provide different outcomes or who might be disproportionately affected by certain conditions. Specific solutions were introduced, including allowing variable cost-sharing and premiums, such as on a sliding scale based on income; offering a preventive medication benefit with a low or \$0 copay; and adjusting cost-sharing models for disease states by which minority or other at-risk populations are disproportionally affected. A system evaluation could also identify opportunities for new or revised programs around payment incentives or disincentives for health care providers who participate in equity efforts; this could enhance accountability for ensuring that these efforts translate into greater equity.

Participants emphasized one crucial consideration, however: the need for any system evaluation to consider how patients access and interact with 


\section{TABLE 3 INTERRUPT Framework to Address Bias and Microaggressions}

\begin{tabular}{|c|c|c|}
\hline & Element & Example phrases \\
\hline I & Inquire: Leverage curiosity. & "I'm curious, what makes you think/say that?" \\
\hline $\mathrm{N}$ & $\begin{array}{l}\text { Nonthreatening: Convey the message with respect. Separate the } \\
\text { person from the action or behavior. Communicate preferences } \\
\text { rather than demands. }\end{array}$ & $\begin{array}{l}\text { "Some may consider that statement to be offensive." } \\
\text { "It would be helpful to me if ..." }\end{array}$ \\
\hline $\mathrm{T}$ & $\begin{array}{l}\text { Take responsibility: If you need to reconsider a statement/action, } \\
\text { acknowledge and apologize. Address microaggressions, and revisit } \\
\text { them if they were initially unaddressed. }\end{array}$ & \\
\hline$E$ & Empower: Ask questions that will make a difference. & "What could you/we do differently?" \\
\hline $\mathrm{R}$ & Reframe & "Have you ever thought about it like this?" \\
\hline $\mathrm{R}$ & $\begin{array}{l}\text { Redirect: Helpful when individuals are put on the spot to speak for } \\
\text { their identity group. }\end{array}$ & "Let's shift the conversation..." \\
\hline $\mathrm{U}$ & Use impact questions & "What would happen if you considered the impact on ...?" \\
\hline $\mathrm{P}$ & Paraphrase: Make what is invisible (unconscious bias) visible. & "It sounds like you think..." \\
\hline $\mathrm{T}$ & Teach by using “I” phrases: Speak from your own experience. & "I felt $x$ when y happened, and it impacted me because..." \\
\hline
\end{tabular}

Source: DallaPiazza et al. ${ }^{9}$

the system and to implement strategies to lessen any advantage or disadvantage to any particular group. An example was to encourage the use of automated tools such as real-time benefit checks and electronic prior authorization whenever possible in order to assist those with less time or fewer resources to navigate benefits and utilization management. It could also include expanding access to the care delivery network, such as by relocating clinics or pharmacies along public transportation lines.

Participants recognized that successful efforts to improve equity in the provision of health care must be committed to patient-centered care. Engaging in both broad and local activities to build trust and increase access among minority populations is one timely example, especially, participants noted, as health care professionals seek to increase adoption of COVID-19 vaccinations. Also important was enhancing care coordination through more systematic engagement of pharmacists, community partners, and health navigators, which could further foster trust, be a way to assess accurately patient-specific social determinants of health, and efficiently address persistent barriers to access, whether they be socioeconomic factors, limited access to health care facilities, interpersonal and systemic racism, or others. Additional examples included enhanced diversity and inclusion among the health care workforce, development of patient outreach programs with simplified materials to improve health and health insurance literacy, and the sharing of best practices and case studies in peer-reviewed journals such as JMCP.
As a follow-on to these considerations, participants suggested methods of ongoing evaluation to assess their effectiveness, including research and the addition of quality metrics specific to equity. Quality metrics could include prior authorization approval and denial rates, adherence among various patient subgroups, or other measures that may be influenced by disparities. These could then be shared via a central data warehouse or communicated by the evaluating entity (eg, Centers for Medicare \& Medicaid Services star ratings).

\section{Policy, Education, and Training Considerations to Advance Equity}

Several policy areas were identified during the discussion as having the potential to affect equity, including those that address data collection standards, those that require nondiscrimination, and those related to clinical trial design and data access. Data collection standards in administrative records, for instance, should be reviewed to determine whether they contribute to or mask inequities; for example, although race may be captured, other characteristics such as gender identity may not be. Also, laws and regulations that require nondiscrimination may unintentionally hinder equity if they prohibit the implementation of more personalized or subgroup formulary or benefit features. Further, there is an opportunity to advance equity with policies related to clinical trial design and data access by aiming for the most representative racial/ethnic populations affected 


\begin{tabular}{|c|c|}
\hline Topics & Considerations \\
\hline Data & $\begin{array}{l}\text { - Increase diversity in clinical trial enrollment, strengthen trial designs to better detect possible heterogeneity among patient } \\
\text { responses, and expand subgroup reporting } \\
\text { - Augment data available within health care delivery systems by, for instance, more thoroughly and efficiently collecting } \\
\text { patient demographic information into medical records } \\
\text { - Recognize that biases may be unintentionally built into current algorithms and artificial intelligence platforms }\end{array}$ \\
\hline $\begin{array}{l}\text { Formulary } \\
\text { process }\end{array}$ & $\begin{array}{l}\text { - Incorporate robust diversity data into drug monograph tools used in formulary development (eg, the AMCP Formulary } \\
\text { Monograph Template) } \\
\text { - Provide annual equity training for pharmacy and therapeutics committee members } \\
\text { - Add committee representation that reflects an organization's minority membership or a member with expertise in equity } \\
\text { - Create a subcommittee to evaluate equity in formulary decisions }\end{array}$ \\
\hline $\begin{array}{l}\text { Benefit } \\
\text { offerings }\end{array}$ & $\begin{array}{l}\text { - Acknowledge and consider that racial disparities may exist in initial benefit design process } \\
\text { - Consider variable cost-sharing and premiums, such as on a sliding scale based on income } \\
\text { - Offer a preventive medication benefit with a low or } \$ 0 \text { copay } \\
\text { - Adjust cost-sharing models in disease states by which minority or other at-risk populations are disproportionally affected }\end{array}$ \\
\hline $\begin{array}{l}\text { Patient } \\
\text { access }\end{array}$ & $\begin{array}{l}\text { - Consider benefit flexibility to improve access } \\
\text { - Use automated tools such as real-time benefit checks and electronic prior authorization to assist those with less time or } \\
\text { fewer resources to navigate benefits and utilization management } \\
\text { - Expand access to the care delivery network, such as by relocating clinics or pharmacies along public transportation lines } \\
\text { - Enhance care coordination through more systematic engagement of pharmacists, community partners, and health navigators } \\
\text { - Develop patient outreach programs with simplified materials to improve health and health insurance literacy }\end{array}$ \\
\hline Others & $\begin{array}{l}\text { - Identify opportunities for new or revised programs around payment incentives or disincentives for health care providers who } \\
\text { participate in equity efforts } \\
\text { - Share best practices and case studies in peer-reviewed journals such as JMCP }\end{array}$ \\
\hline
\end{tabular}

by the condition being studied and increasing the role of real-world data to allow understanding of and track disparities in medication access.

As these current policies may need to evolve or new policies may need to be developed, participants thought it was important to continue fostering relationships, better communication, and increased understanding between regulators and managed care stakeholders, including patients or advocates who are familiar with racial health disparities. They also suggested that a set of core principles for policy development be established. For participants, policy reform plays a key role in aligning incentives, especially between payers and physicians as they seek to implement innovations to increase equity.

Education and training are also central to addressing equity gaps. Participants indicated the importance both of foundational education for all health care stakeholders about why inequities exist and persist and of updates to health sciences educational curricula. They also noted that patient-related education about, for example, health insurance literacy could provide opportunities to strengthen relationships between health care providers and communities. As with all proposed considerations, it will be important to assess any such education program to determine whether it achieves its intended objectives.

In addition to annual equity training for pharmacy and therapeutics committees, participants considered training to be necessary across all aspects of health care, with an intentional focus on leadership training. Effective equity training would include topics such as related terminology (Table 1), structural racism, implicit bias, and cultural competency, among others. For the managed care industry specifically, training on equity best practices, trust in data and good practices for data utilization, and transparency to outside stakeholders would also be valuable.

\section{Conclusions}

The health disparities derived from racism and social determinants of health that exist in the United States are deeply rooted and complex. To begin mitigating these disparities as they relate to benefit design, this forum's participants noted that it is critical to acknowledge that systemic racism 
exists, to integrate proactive strategies to improve equity, and to view patients holistically.

Participants also proposed considerations in priority areas such as mitigating existing gaps in clinical trial and health care delivery system data, increasing diversity and equity in formulary development and benefit offerings, and improving access for patients in disadvantaged groups. Additionally, education and training on topics such as equity-related terminology, systemic racism, implicit bias, and cultural competency were highlighted as vital to effective equity efforts. Evolving current policies and developing new policies are opportunities to positively impact equity.

\section{DISCLOSURES}

This forum was sponsored by Amgen, the National Pharmaceutical Council, Pfizer, PhRMA, Sandoz, and Takeda. Their representatives joined the forum as panelists or participants. These proceedings were prepared as a summary of the forum to represent common themes; they are not necessarily endorsed by all attendees nor should they be construed as reflecting group consensus.

\section{ACKNOWLEDGMENTS}

This AMCP Partnership Forum was moderated by Clifford Goodman, PhD. These proceedings were written by Bridget Flavin, PharmD, Founder, Connected Content, Ltd. Connected Content, Ltd., received payment from AMCP for the preparation of this manuscript. Flavin is also an employee of IngenioRx and an adjunct associate professor at the University of Florida College of Pharmacy.

\section{REFERENCES}

1. Centers for Disease Control and Prevention. Demographic trends of COVID-19 cases and deaths in the US reported to CDC. Accessed July 25, 2021. https://covid.cdc.gov/ covid-data-tracker/\#demographics

2. Academy of Managed Care Pharmacy. AMCP unites with national pharmacy organizations to stand against injustice. June 5, 2020. Accessed July 25, 2021. https://www.amcp.org/policy-advocacy/ letters-statements-analysis/amcp-unitesnational-pharmacy-organizations-stand

3. Cantrell SA. AMCP stands against racial injustice. AMCP blog. June 18, 2020. Accessed July 25, 2021. https:// www.amcp.org/Resource-Center/blog/ amcp-stands-against-racial-injustice

4. Cantrell SA. Finding inspiration to address health disparities. AMCP blog. October 44, 2021. Accessed July 25, 2021. https://www.amcp.org/ Resource-Center/blog/finding-inspiration-address-health-disparities

5. Racial disparities in medication use: JMCP's response and call for submissions. J Manag Care Spec Pharm. 2020;26(11):1475-76. doi:10.18553/ jmcp.2020.26.11.1475

6. Kogut SJ. Racial disparities in medication use: imperatives for managed care pharmacy. J Manag Care Spec Pharm. 2020;26(11):1468-1474. doi:10.18553/ jmcp.2020.26.11.1468
7. Academy of Managed Care Pharmacy. AMCP strategic priorities - introduced Spring 2021. Accessed July 28, 2021. https://www.amcp.org/about/ about-amcp/amcp-strategic-priorities

8. Hoffman KM, Trawalter S, Axt JR, Oliver MN. Racial bias in pain assessment and treatment recommendations, and false beliefs about biological differences between blacks and whites. Proc Natl Acad Sci U S A. 2016;113(16):4296-4301. doi:10.1073/pnas.1516047113

9. DallaPiazza M, Padilla-Register M, Dwarakanath M, Obamedo E, Hill J, Soto-Greene ML. Exploring racism and health: an intensive interactive session for medical students. MedEdPORTAL. 2018;14:10783. doi:10.15766/ mep_2374-8265.10783

10. Edward J, Wiggins A, Young MH, Rayens MK. Significant disparities exist in consumer health insurance literacy: implications for health care reform. Health Lit Res Pract. 2019;3(4):e250-e258. doi:10.3928/24748307-20190923-01

11. Jones CP. Levels of racism: a theoretic framework and a gardener's tale. Am J Public Health. 2000;90(8):1212-1215. doi:10.2105/ajph.90.8.1212 